\title{
Ankyloblepharon filiforme adnatum affecting identical twins
}

\author{
JOHN HOWE AND BRIAN HARGOURT
}

From the Department of Ophthalmology, University of Leeds, and the General Infirmary, Leeds

In this rare congenital abnormality, first described by Hasner (I88I), single or multiple fine strands of tissue join together parts of the upper and lower eyelid margins. These bands arise from the 'grey line', posterior to the cilia but in front of the orifices of the meibomian glands; this is in contradistinction to other forms of developmental ankyloblepharon, in which sheets of tissue that are continuous with the eyelid skin form broad adhesions between the lids.

This communication gives the first description of this developmental defect affecting identical twins, and includes a brief note on the spontaneous regression and final resolution of the adhesions which occurred during the first few months of life.

\section{Case reports}

Identical twin boys were first examined in the Paediatric Ophthalmic Clinic at Leeds General Infirmary at the age of 2 months, with a history that the upper and lower eyelids on both sides and in both babies had been joined at birth by a number of fine 'tags of skin'. The adhesions on the right side had separated completely before the end of the first month of life, in one twin 2 days before the other, but had persisted on the left side in both cases. The children had been born at 34 weeks' gestation by normal delivery, weighing I,850 and I,900 g. respectively; the second twin had made a good recovery from initial respiratory distress, and his brother had remained healthy throughout. There was no family history of eyelid anomalies, and no parental consanguinity.

\section{Examination}

At the age of 2 months TwIN I exhibited three fine bands of tissue joining the grey lines of the left upper and lower eyelids (Fig. I). These were $1.5 \mathrm{~mm}$. broad and $2 \mathrm{~mm}$. long in the relaxed state, but when the lids were separated as much as possible by traction, the bands increased in length to $4 \mathrm{~mm}$. The right upper and lower lids showed no abnormality; the eyelashes were also normal and there was no blepharitis. The pupil was clearly visible on slight downward gaze on the affected side, and the media and fundi of both eyes were entirely healthy in appearance. TwIN II showed almost identical features (Fig. 2).

\section{Progress}

As there was no evidence of squint and the eyelid adhesions were not completely obstructing the visual axes, it was considered that there was no risk of amblyopia developing in either eye. Since the eyelids had separated spontaneously on the right side a conservative approach was adopted. 


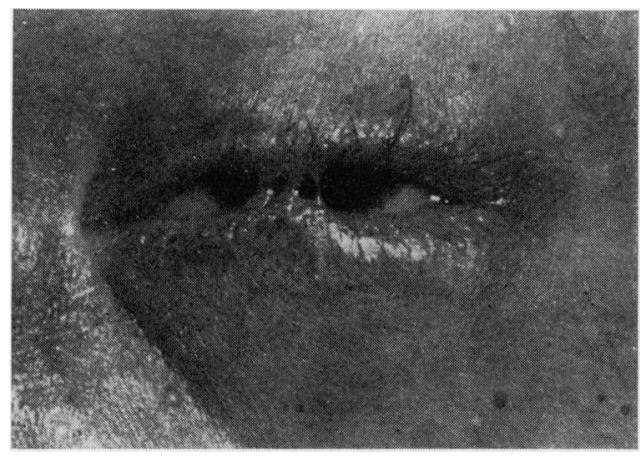

FIG. I Left eyelids of Twin I at the age of 2 months

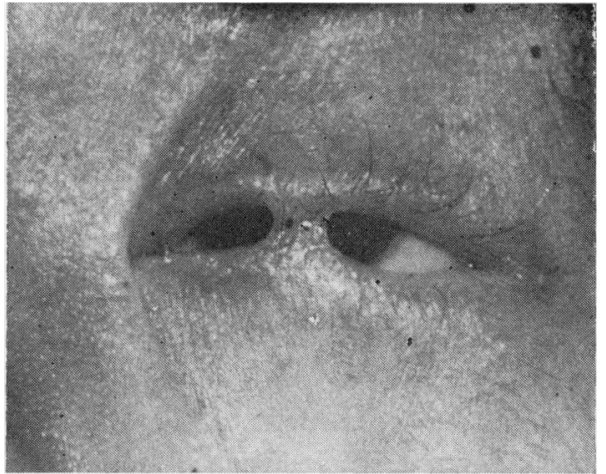

FIG. 2 Left eyelids of Twin II at the age of 2 months

The children were re-examined 6 weeks later. Two bands were then present in each child, and these were only I $\mathrm{mm}$. wide. When a further examination was carried out at the age of 4 months a spontaneous total separation of the left eyelids was reported to have occurred in Twin I on the previous day (Fig. 3). One fine band only, which was less than I mm. wide, persisted in Twin II (Fig. 4); this also resolved spontaneously less than I week later.
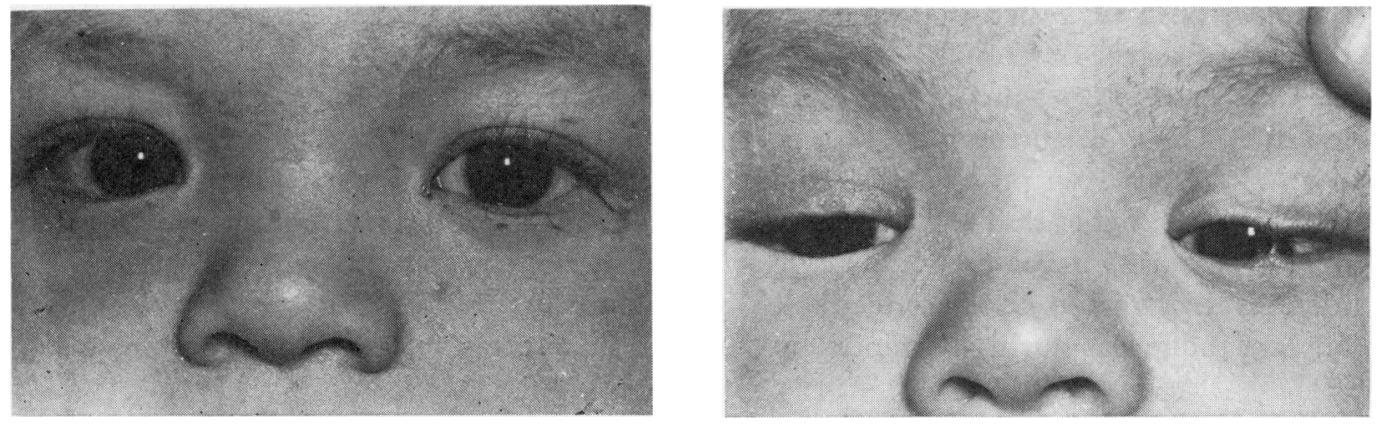

FIG. 3 Eyelids of Twin I at the age of 4 months, the day after complete separation of the lid margins had occurred

FIG. 4 Eyelids of Twin II at the age of 4 months; the residual interpalpebral adhesion on the left side resolved spontaneously I week later

Result

The interpalpebral adhesions had therefore resolved completely within 2 days of each other on the right side in both twins, and within a week of each other on the left side. No residual lid anomalies now affect either child, and ocular and general examination remains unremarkable.

\section{Discussion}

Congenital filiform ankyloblepharon has previously been described as affecting two sisters, one of whom also had hare-lip and cleft palate (Khanna, 1957), but the present report is the first to describe the condition as occurring in identical twins. The spontaneous regression and resolution of the bands has also previously gone unreported, and this is probably because they are so easily severed surgically. The description of this resolution and the fact that the events followed a very similar time sequence in the two affected twins is noteworthy.

Histological examination of the adhesions in previous cases of ankyloblepharon filiforme adnatum has shown that they consist of a central core of vascular connective tissue surround- 
ed by stratified squamous epithelium with no evidence of inflammatory reaction (Wintersteiner, 1908). This vascular core explains the brisk bleeding which occurs whenever the bands are cut. On account of the traction of the eyelids exerted during blinking, the adhesions are thinner centrally than at their insertions, and are also of variable dimensions, stretching to twice their relaxed length when they are under tension. No bleeding occurred in association with the spontaneous separation of the bands which took place in the children described in this report, suggesting that there is a gradual atrophy of the connective tissue core before separation.

Associated developmental defects have been reported in some cases of ankyloblepharon filiforme adnatum -in particular such cardiac anomalies as patent ductus arteriosus and interventricular septal defect (Lobstein and Haarscher, I953; Rogers, I96I) and hare-lip (Khanna, 1957; Lohlein, I930; Long and Blandford, 1962; Ehlers and Jensen, 1970). No associated congenital abnormalities were noted in either of the twins described in this report.

There has in the past been some dispute regarding the aetiology of these fine extensile congenital interpalpebral adhesions. It was originally suggested (Hasner, I88I) that they were the result of intrauterine inflammation, but subsequent histological examinations (Wintersteiner, 1908; Rogers, 1961; Long and Blandford, 1962) showed no evidence of inflammatory changes. The connections cannot simply be a persistence of the normal temporary fusion of the eyelids which occurs in foetal life, as this is solely epithelial. It has therefore been suggested that, at the stage of development of lid fusion, there is either a temporary arrest in growth of epithelium or a more rapid than usual proliferation of mesoderm which permits areas of abnormal mesodermal union between the upper and lower eyelids with surrounding, but not interposed, ectoderm (Judge, Mott and Gabriels, 1929). Previous descriptions of the familial incidence of filiform ankyloblepharon have given weight to the belief that the defect is the result of inherited rather than acquired factors operating during development. The present report does nothing to resolve the question, as identical twins could be affected equally by hereditarily determined factors or by acquired adverse influences during development, to give rise to the eyelid abnormalities described.

\section{Summary}

Healthy identical twin boys were both affected by bilateral ankyloblepharon filiforme adnatum. The lid adhesions resolved spontaneously and completely during the first 4 months of life, following the same sequence in both children.

\section{References}

Ehlers, N., and Jensen, I. K. (1970) Acta ophthal. (Kbh.), 48, 465

haSNer, v. (188I) Z. Augenheilk., 2, 429

JUDGe, H. W., MOTt, w. c., and GABRIELS, J. A. c. (1929) Arch. Ophthal. (Chicago), 2, 702

khanna, v. N. (1957) Amer. 7. Ophthal., 43, 774

LOBSTEIN, A., and HAARSGHER, A. (1953) Bull. Soc. franc. Ophtal., 2, I 28

LOHLEIN, W. (1930) "Kurzes Handbuch der Ophthalmologie", vol. 3, p. 252. Springer, Berlin

LONG, J. C., and BLANDFORD, s. E. (1962) Amer. F. Ophthal., 53, I 26

ROGERs, J. W. (196I) Arch. Ophthal. (Chicago), 65, i 14

Wintersteiner, H. (1908) Arch. Augenheilk., 59, 196 